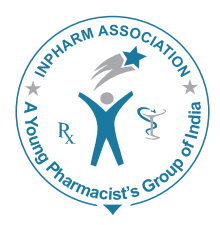

\title{
Anti-epileptic drug utilization and treatment outcome among epileptic patients on follow-up in a resource poor setting
}

\author{
Mesfin Gurshaw ${ }^{1}$, Asrat Agalu², Tesfahun Chanie ${ }^{1 *}$ \\ ${ }^{1}$ Department of Clinical Pharmacy, School of Pharmacy, Jimma University, Jimma, Ethiopia, \\ ${ }^{2}$ Department of Pharmacy, Wollo University, Dessie, Ethiopia
}

\begin{abstract}
Introduction: Anti-epileptic drugs (AEDs) are the primary therapeutic modes for epileptic patients and have been demonstrated to control seizure, which decreases morbidity and mortality associated with epilepsy. There is a paucity of data on treatment outcome among epileptic patients in resource poor settings. The aim of this study was to assess AED utilization pattern and treatment outcome among epileptic patients on follow-up. Materials and Methods: A retrospective cross-sectional study was conducted among epileptic patients on follow-up at Epilepsy clinic of Jimma University specialized hospital. A total of 290 patient record cards which had 3 years of follow-up information was used to evaluate AED utilization pattern and treatment outcome through medical records review. Results: From a total 290 cards of epileptic patients on follow-up, $170(58.6 \%)$ were males. The common type of seizure diagnosed was generalized tonic clonic seizure, $232(80 \%)$. Monotherapy was commonly used in the management of seizure, $54.5 \%$, among which phenobarbitone was the most commonly utilized single anticonvulsant drug. One hundred and sixty-five (56.7\%) patients were seizure free during follow-up periods and 125 (43.3\%) patients were not, of which $121(73.3 \%)$ of patients had 1 up to 5 seizure attacks per 3 months during the 3 years follow-up period. Conclusion: All studied epileptic patients were put on traditional AEDs; phenobarbitone being the most frequently prescribed single drug. About one in every two epileptic patients evaluated were seizure free during the 3 years follow-up period.
\end{abstract}

Key words: Anti-epileptic drugs utilization, epilepsy, ethiopia, seizure outcome

\section{INTRODUCTION}

Epilepsy is a major health concern worldwide. It is a chronic disorder characterized by recurrent seizures and second most common chronic neurologic disorder

\begin{tabular}{|c|c|}
\hline \multicolumn{2}{|c|}{ Access this article online } \\
\hline Journal Sponsor & \multirow[b]{2}{*}{$\begin{array}{l}\text { Website: } \\
\text { www.jyoungpharm.org }\end{array}$} \\
\hline \multirow{2}{*}{ wuw.phcog net } & \\
\hline & $\begin{array}{l}\text { DOI: } \\
\text { 10.5530/jyp.2014.3.8 }\end{array}$ \\
\hline
\end{tabular}

seen by neurologists. It is diagnosed clinically based on signs and symptoms, and its management is based on identification of goals, assessment, development of care plan and follow-up evaluation. Thus, it is critical to establish an accurate diagnosis of the seizure type and classification prior to therapeutic management to individualize drug therapy with the ultimate goal of improving quality of patients' life by seizure free periods, and minimizing side effects. ${ }^{1-9}$ Uncontrolled seizures may be associated with adverse effects, psychiatric co-morbidities, and cognitive impairment resulting in employment restriction, physical injuries and finally to death. ${ }^{10}$

*Address for correspondence:

Mr. Tesfahun Chanie, Clinical Pharmacist and Lecturer, Department of Clinical Pharmacy, School of Pharmacy, Jimma University,

Jimma,Ethiopia.E-mail:tesfuc@gmail.com 
Treatment with anti-epileptic drug (AED) is selected based on the type of seizure and is to be continued till the patient is seizure free often for 1-5 years. However, about $90 \%$ of epileptic patients in developing countries are not receiving appropriate treatment due to the cultural attitude, lack of prioritization, poor health care system, economic problems and inadequate supply of AEDs. ${ }^{11-14}$

Treatment outcome depends on several factors such as drug related factors, disease-related factors and patient-related factors. Drug-related factors include pharmacokinetics of the drugs, drug-drug interactions and toxicity among others. Similarly, irrational prescribing will result in poor treatment outcome. Thus, in only $70 \%$ of children and $60 \%$ of adults the seizure was completely controlled with AEDs. To withdraw AED patient has to be seizure free for 3-4 years since sudden withdraw increases seizure frequency and severity. ${ }^{11,15-20}$

Though different studies have been conducted in different parts of the world including Africa, to our knowledge analysis of treatment outcome among epileptic patients in the general hospitals of Ethiopia was not well studied except in particular wards and disease conditions. This is particularly true in the study. Thus, the aim of this study was to assess AED utilization pattern and treatment outcomes among epileptic patients visiting the epileptic clinic of Jimma University Specialized Hospital (JUSH).

\section{MATERIALS AND METHODS}

\section{Study area and period}

Retrospective cross-sectional study was conducted in JUSH from January 28 to February 8, 2013. JUSH is located in Jimma town, $346 \mathrm{~km}$ from Addis Ababa in Southwest Ethiopia. JUSH, established in 1930, is one of the oldest public hospitals in the country. Currently, it is the only teaching and referral Hospital in South-western Ethiopia comprising more than 750 staffs. It provides specialized service for approximately 9000 inpatients and 800000 attendants in a year. ${ }^{21}$

\section{Study participants}

Two hundred and ninety adult epileptic patients' record cards were selected from total records and those selected cards from 2010 to 2012 were included in the study. Adult record cards which had no follow-up data and pediatric record cards were excluded from the study. Systematic random sampling technique was used to select the study population. The sample size to be taken for the study was determined by using the following formula. ${ }^{22}$

$n=\frac{Z^{2} 1-\alpha / 2 P(1-p)}{d^{2}}$

Where, $n=$ sample size

$Z=$ confidence interval (1.95)

$p=$ estimated prevalence $(0.5)$

$d=$ Margin of error to be tolerated (0.05).

Based on the above formula and using 95\% confidence

$n=\frac{Z^{2} 1-\alpha / 2 P(1-p)}{d^{2}}$

$n=\frac{(1.96)^{2}(0.5)(0.5)}{(0.05)^{2}}=384$

since the total population is $<10,000$ the sample was recalculated based on the following formula:

$1+n / N$

$\mathrm{n}=$ sample size, $\mathrm{Nf}=$ actual sample size

$\mathrm{N}=$ total number of adult epileptic patients who attend epilepsy clinic of JUSH, $(N=1200)$.

Therefore, the sample size was: $\mathrm{Nf}=1+384 / 1200=290$.

\section{Data collection process and statistical analysis}

Pre-tested well-structured data collection format was designed to collect data from the patient cards including patient demographics, type of drug and treatment outcomes. Data were collected by the principal investigator. The collected data were cleared, categorized and analyzed using Statistical Package for the Social Sciences version 19 (Chicago, IL, USA) for Microsoft window, and the results were presented in tables and figures as necessary. Descriptive analysis was used to describe the percentages and number distributions of variables.

\section{Ethical considerations}

The management of the hospital was requested for permission by a formal letter from the University. Names of physicians involved in the health care provision and those of patients were replaced by initials. All data obtained in the course of the study were kept confidential, and used solely for the purpose of the study. 


\section{RESULTS}

\section{Socio-demographic characteristics}

A total of 290 patient medical records were included in the retrospective study. The demographic data revealed that the number of male and female patients were $170(58.6 \%)$ and $120(41.4 \%)$ respectively, among these $16-30$ and $31-45$ years of age groups, are more prevalent that accounted $114(39.2 \%)$ and $85(29.2 \%)$, respectively (Table 1$)$.

\section{Classification of epileptic seizures}

Generalized tonic-clonic seizure (GTCS) accounted about $232(80 \%)$, followed by unknown type of epilepsy, $44(15.17 \%)$ (Table 2$)$.

\section{AED utilization pattern}

Monotherapy was commonly used in the management of seizure which accounted $54.5 \%$, followed by dual therapy, $35.9 \%$. The least commonly used was treatment that included 4 drugs (phenobarbitone, phenytoin, carbamazepine and valproic acid) which accounted about $2 \%$ from the total patients. The most common drug that is used in monotherapy was phenobarbitone (Table 3).

Regarding the number of AEDs prescribed, from a total of 456 prescribed AED drugs, corresponding to an average

Table 1: Socio-demographic characteristics of epileptic patients on follow-up at epilepsy clinic of JUSH from January 2010 to December 2012

\begin{tabular}{lc}
\hline Socio-demographic variables & Frequency, $\boldsymbol{N}(\%)$ \\
\hline Sex & \\
Male & $170(58.6)$ \\
Female & $120(41.4)$ \\
Total & $290(100)$ \\
Age at the time of diagnosis & \\
1 -15 & \\
Male & $9(3.1)$ \\
\hline Female & $12(4.2)$ \\
\hline $16-30$ & \\
\hline Male & $60(20.6)$ \\
\hline Female & $54(18.6)$ \\
\hline $31-45$ & \\
\hline Male & $51(17.5)$ \\
\hline Female & $34(11.7)$ \\
\hline $46-60$ & \\
\hline Male & $44(15.1)$ \\
\hline Female & $18(6.2)$ \\
\hline 60 & \\
\hline Male & $6(2)$ \\
\hline Female & $2(0.2)$ \\
\hline Total & $290(100)$ \\
\hline
\end{tabular}

JUSH: Jimma University Specialized Hospital of 1.57 AEDs per patient, phenobarbitone accounted about $284(62.3 \%)$ with a dose range of $50-600 \mathrm{mg} /$ day, followed by phenytoin with a dose range of $40-500 \mathrm{mg} /$ day, $141(30.9 \%)$. The utilization profile of anti-epileptics for the treatment of different types of epileptic seizures is summarized in Table 4.

\section{Adverse effects of AEDs}

Hundred (33.4\%) patients reported that they had experienced adverse effects related to his/her AED therapy. Headache was the commonest adverse effect recorded, 21 (21.6\%), followed by epigastric pain, $18(18.5 \%)$ and

Table 2: Distribution of the types of epileptic seizures at epilepsy clinic of JUSH from January 2010 to December 2012

\begin{tabular}{lc}
\hline Type of seizure & Frequency, $\boldsymbol{N}(\%)$ \\
\hline GTCS (grandmal) & $232(80)$ \\
US* & $44(15.17)$ \\
CPS & $5(1.72)$ \\
AS & $4(1.37)$ \\
TCS & $3(1.03)$ \\
AS & $1(0.35)$ \\
GTS & $1(0.35)$ \\
Total & $290(100)$ \\
\hline
\end{tabular}

*The assessment written just as epilepsy without categorization

of the seizure type. JUSH: Jimma University Specialized Hospital,

GTCS: Generalized tonic clonic seizure, CPS: Complex partial seizures,

GTS: Generalized tonic seizures, As: Atonic seizures, AS: Absence

seizure, TCS: Tonic-clonic seizures, US: Unclassified seizures

Table 3: Distribution of mode of AEDs therapy based on the type of seizure atepilepsy clinic of JUSH from January 2010 to December 2012

\begin{tabular}{lcccc}
\hline AED therapy & \multicolumn{2}{c}{ Number of patients } & US & Total (\%) \\
\cline { 2 - 4 } & $\begin{array}{c}\text { Partial } \\
\text { seizures }\end{array}$ & $\begin{array}{c}\text { Generalized } \\
\text { seizures }\end{array}$ & & \\
\hline Monotherapy & 2 & 135 & 21 & $158(54.5)$ \\
Dual therapy & 3 & 87 & 14 & $104(35.9)$ \\
Triple therapy & 0 & 12 & 10 & $22(7.6)$ \\
Quadruple therapy & 0 & 6 & 0 & $6(2)$ \\
Total & 5 & 240 & 45 & $290(100)$ \\
\hline
\end{tabular}

JUSH: Jimma University Specialized Hospital, US: Unclassified seizures, AED: Anti-epileptic drug

Table 4: Number of AEDs prescribed as per the type of seizure in epilepsy clinic of JUSH from January 2010 to December 2012

\begin{tabular}{lccccccccc}
\hline AEDs & \multicolumn{6}{c}{$\begin{array}{c}\text { Number of drugs per the type of } \\
\text { seizure }\end{array}$} & $\begin{array}{c}\text { Dose } \\
(\mathbf{m g} / \mathbf{d})\end{array}$ \\
\cline { 2 - 8 } & GTCS & CPS & US & AS & TCS & As & GTS & Dose range \\
\hline Phenobarbital & 232 & 2 & 40 & 5 & 3 & 1 & 1 & $15-600$ \\
Phenytoin & 106 & 3 & 25 & 3 & 3 & 0 & 0 & $50-400$ \\
Carbamazepine & 18 & 1 & 4 & 1 & 0 & 0 & 0 & $100-1000$ \\
Vapoiric acid & 6 & 0 & 0 & 1 & 1 & 0 & 0 & $200-1000$ \\
Total & 361 & 6 & 70 & 10 & 7 & 1 & 1 & \\
\hline
\end{tabular}

TCS: Tonic-clonic seizures, JUSH: Jimma University Specialized Hospital, US: Unclassified seizures, AEDs: Anti-epileptic drugs, GTCS: Generalized tonic clonic seizure, CPS: Complex partial seizures, GTS: Generalized tonic seizures, As: Atonic seizures, AS: Absence seizure 
confusion, 17 (17.5\%). The least frequently reported adverse effects, as documented in the record card; include forgetfulness, skin rash, depression and gingival hypertrophy, 2 (2.1\%) patients (Table 5).

\section{Seizure frequency and treatment outcome}

From 290 epileptic patients, 165 (56.7\%) patients were seizure free and $125(43.3 \%)$ were not free during the 3 follow-up years. Among those not free, most patients experienced 1-5 seizure attacks, which accounted about 121 patients $(73.3 \%)$ followed by $6-10$ attacks per 3 months in which $30(18.2 \%)$ patients are experienced during 3 years follow-up (Table 6).

\section{Patient hospitalization during follow-up periods}

From 290 patients studied, 11 (3.8\%) patients were hospitalized during the 3 years follow-up period, among which seven were hospitalized due to status epileptics and four were hospitalized due to other reasons. From those patients hospitalized due to status epileptics, 1 patient had absence seizure, 4 patients had GTCS and 2 patients had

Table 5: Adverse effects faced by the patient at epilepsy clinic of JUSH from January 2010 to December 2012

\begin{tabular}{lc}
\hline Adverse effect experienced & Frequency, N (\%) \\
\hline Headache & $21(21.6)$ \\
Epigastric pain & $18(18.5)$ \\
Confusion & $17(17.5)$ \\
Weakness & $12(12.3)$ \\
Blurring of Vision & $11(11.8)$ \\
Irritability & $6(11.3)$ \\
Nightmare & $4(4.1)$ \\
Forgetfulness & $2(2.1)$ \\
Skin rash & $2(2.1)$ \\
Depressed mood & $2(2.1)$ \\
Gingival hypertrophy & $2(2.1)$ \\
Total & $97(100)$ \\
\hline
\end{tabular}

JUSH: Jimma University Specialized Hospital

Table 6: Number of seizure attacks experienced for those who are not seizure free per each 3 follows-up month period among epileptic patients at JUSH from January 2010 to December 2012

\begin{tabular}{lcccc}
\hline Type of & Number & \multirow{2}{*}{$\begin{array}{c}\text { of } \\
\text { seizure }\end{array}$} & \multicolumn{3}{c}{$\begin{array}{c}\text { Number of seizure attacks per } \\
\text { p months, } \boldsymbol{N}(\%)^{* *}\end{array}$} \\
\cline { 3 - 5 } & patients & $\mathbf{1 - 5}$ attacks & $\mathbf{6 - 1 0}$ attacks & $>\mathbf{1 0}$ attacks \\
\hline AS & 3 & $3(2.5)$ & 0 & 0 \\
GTC & 139 & $108(89.2)$ & $20(66.6)$ & $11(78.6)$ \\
CPS & 2 & $1(0.8)$ & $1(3.3)$ & 0 \\
TCS & 1 & $1(0.8)$ & 0 & 0 \\
Unknown & 20 & $8(6.6)$ & $9(30)$ & $3(21.4)$ \\
Total & 165 & 121 & 30 & 14 \\
\hline
\end{tabular}

${ }^{* *}$ The number of seizure attacks per 3 months in the whole 3 years follow-up, GTC: Generalized tonic seizures, CPS: Complex partial seizures, AS: Absence seizure, JUSH: Jimma University Specialized Hospital, TCS: Tonic-clonic seizures an unknown seizure. The main reasons for hospitalizations among these seven patients were due to medication nonadherence, i.e., missing of doses.

\section{DISCUSSION}

According to this study result, GTCS was the most common type of epileptic seizure encountered which accounted about $232(80 \%)$. This result is different from a study done on drug use evaluation (DUE) of AEDs at a multispecialty tertiary care teaching hospital in India in which GTCS is about $(55.22 \%){ }^{6}$ The difference may be associated with the presence of neuroimaging methods that can facilitate proper classification and diagnosis. Second, in our study uncategorized epilepsy which accounted about 44 (15.17\%) of the sample population might have contributed to the specific types if the facility has the capacity to categorize the specific type of seizure. The choice of the most appropriate AEDs depends on the proper classification of seizures and the type of epilepsy or epileptic syndromes. Lack of proper classification of seizure type affects treatment outcome and selection of drugs. In our study, a significant proportion of epileptic patients' specific category of the type of seizure is not recorded that might affect the selection of appropriate AEDs selection. This requires due attention to help clinicians to identify the specific seizure type.

Most patients with epilepsy respond to one of the firstline AEDS; second-line agents may be useful in patients who do not respond to one or a combination of the firstline agents. In this study, phenobarbitone was the firstline drug prescribed, as mentioned in national treatment guideline, followed by phenytoin in generalized seizure. The best AED therapy is dependent on optimal seizure control and absence of unacceptable side-effects. ${ }^{23}$ This is in contrary to the recent evidenced based treatment recommendation for newly diagnosed epilepsy in developed countries, as phenobarbitone is considered a second/third line option.

It is important to maintain patients on monotherapy as compliance is better, side effects are less and there is no problem of drug-drug interaction. In our study, monotherapy $(54.5 \%)$ was followed by dual therapy $(35.9 \%)$. A study done in UK and Singapore showed that the majority of the patients were on monotherapy $(63 \%){ }^{23}$ When our result was compared with the above study, there is a variation in drug utilization, and this might be associated with the presence of health care providers specialized in pharmacotherapy of epilepsy and the availability of first line AEDs recommended in recent guideline. However, 
in our study, phenobarbitone was the most frequently prescribed monotherapy, followed by phenytoin. In contrast, carbamazepine was the commonest AED used in monotherapy or in combination therapy, followed by valproate and phenobarbitone in Singapore. Phenytoin with phenobarbitone was the most frequent 2-drug combination in our study. Even though combination of phenytoin and phenobarbitone is important in maximum control of seizure occurrence, the risk of combined toxicity is high.

Polytherapy offers no advantage over monotherapy. It increases the potential for drug-drug interactions, results in failure to evaluate the individual drugs, can increase the risk of chronic toxicity (including neurocognitive problems), may affect compliance and is associated with a higher cost of medication and necessity for therapeutic drug monitoring. ${ }^{24}$

As the adverse effects data retrieved from patient medical records showed, it is very likely that adverse effect reporting was under estimated. Most accurate data could have been obtained by questioning the patient directly. From 97 patients complaining side effect, headache was the most common adverse effect faced by $21(21.6 \%)$ patients, which was followed by epigastric pain $18(18.5 \%)$ patients and confusion $17(17.5 \%)$ patients. Though most patients complain headache, severe adverse effects had been occurred in $2(2.1 \%)$ patients and was gingival hypertrophy due to phenytoin. A study done on DUE on anti-epileptics at multispecialty tertiary teaching hospital in India, showed that 16 patients reported adverse drug reactions (ADR) related to his/her anti-epileptic therapy: phenytoin was involved in seven ADRs (rash, urticaria, ataxia, Steven Johnson syndrome, gingival hypertrophy), carbamazepine (crash, macolo, popular rash), and oxcarbazepine (hyponatremia, osteoporosis, rash), was reported in four patients. Sodium valproate was involved in one ADR (rash). ${ }^{24}$

Regarding seizure treatment outcome in terms of seizurefreedom, this study showed that almost $57 \%$ of patients were found to be seizure free for a consecutive 3 years follow-up periods. This study showed that conventional AEDs were still safe and effective for seizure control among a substantial segment of epileptic patients in resource-poor setting. For these groups of patients who achieved adequate seizure control, there must be a consideration of clinical assessment to either taper the dose of the AEDs or to withdraw AED treatment after investigations is done for intellect, neuro imaging and encephalography if possible. When compared to a study done on seizure frequency in medically treated adult epilepsy patients $(N=934)$ in
Cleveland clinic, USA, $63 \%$ of patients were completely seizure-free at 6 months, and 64\% were completely seizurefree at 12 months, our data of seizure freedom was slightly lower though this study looked only for a period of 1 year. ${ }^{25}$ For the remaining $43 \%$ patients who did not achieve seizure free in our study, still adequate support should be given either through reconsideration of AEDs being selected or dose optimization and/or reinforcing medication adherence, some patients' epilepsy might also be drug resistant type, which will have a significant extra cost and disease burden. They need to be assessed to look for any exacerbating factors to adequately control the seizure.

\section{CONCLUSIONS}

In this study GTCS was the most prominent seizure encountered. Monotherapy was most frequently used mode of AED therapy in most of the epileptic seizures. The most common adverse effect patients faced while the follow-up period was headache. The most commonly prescribed AED was phenobarbitone, followed by phenytoin. Of epileptic patients in the study, around $57 \%$ of patients were seizure free during 3 follow-up years. This study showed that for a considerable number of epileptic patients, conventional AEDs were still safe and effective in achieving seizure control in resourcepoor settings. Patients having a hospitalization during the follow-up period; most of them were due to status epileptics. Though using monotherapy is encouraged in terms of reducing side effects, reducing drug interactions and increasing compliance, its practice should be based on accurate diagnosis and classification of seizure types and adhering to the national guideline on prescribing protocols developed to reduce AEDs selection errors.

\section{REFERENCES}

1. Scottish Intercollegiate Guidelines Network. Diagnosis and management of epilepsy in adults. Edinburgh (Scotland): A National Clinical Guideline; 2003. p. 49.

2. Leppik IE. Contemporary Diagnosis and Management of the Patient with Epilepsy. $2^{\text {nd }}$ ed. Newtown, PA: Handbooks in Health Care; 1996.

3. Sridharan R. Epidemiology of epilepsy. Curr Sci 2002;82:664-70.

4. Tekle-Haimanot R, Forsgren L, Ekstedt J. Incidence of epilepsy in rural central Ethiopia. Epilepsia 1997;38:541-6.

5. Brodie MJ, French JA. Management of epilepsy in adolescents and adults. Lancet 2000;356:323-9.

6. Sridharan R, Radhakrishnan K, Ashok PP, Mousa ME. Epidemiological and clinical study of epilepsy in Benghazi, Libya. Epilepsia 1986;27:60-5.

7. Herks GK. Antiepileptics clinical applications. Aust Prescr 1994;17:9-12.

8. Vickrey BG, Hays RD, Rausch R, Sutherling WW, Engel J Jr, Brook RH. Quality of life of epilepsy surgery patients as compared with outpatients with hypertension, diabetes, heart disease, and/or depressive symptoms. Epilepsia 1994;35:597-607.

9. Perucca P, Hesdorffer DC, Gilliam FG. Response to first antiepileptic drug 
trial predicts health outcome in epilepsy. Epilepsia 2011;52:2209-15.

10. Gilliam F. Optimizing health outcomes in active epilepsy. Neurology 2002;58:S9-20.

11. Daniel H. Lowenstein: Seizures and epilepsy: In: Kasper DL, Braunwald E, Fauci AS, Hauser SL, Longo DL, Jameson JL, editors. Principles of Internal Medicine. 16 $6^{\text {th }}$ ed., Vol. 2. New York: The McGraw-Hill Companies; 2005. p. 2356.

12. Scott RA, Lhatoo SD, Sander JW. The treatment of epilepsy in developing countries: Where do we go from here? Bull World Health Organ 2001;79:344-51.

13. Heaney DC, Beran RG, Halpern MT. Economics in epilepsy treatment choices: Our certain fate? Epilepsia 2002;43:32-8.

14. García-Morales I, Sancho Rieger J, Gil-Nagel A, Herranz Fernández JL. Antiepileptic drugs: From scientific evidence to clinical practice. Neurologist 2007;13:S20-8.

15. Joint Commission on the Accreditation of Health Care Organizations. 1995 Compressive Accreditation Manual for Hospitals. Oakbrook Terrace (IL): Joint Commission on the Accreditation of Health Care organizations; 1994.

16. Schachter SC, Cramer GW, Thompson GD, Chaponis RJ, Mendelson MA, Lawhorne L. An evaluation of antiepileptic drug therapy in nursing facilities. J Am Geriatr Soc 1998;46:1137-41.

17. Wyllie E. The treatment of Epilepsy, Principles \& Practice. $3^{\text {rd }}$ ed.
Philadelphia: Lippincott Williams, Wilkins; 2001.

18. Garrard J, Cloyd J, Gross C, Hardie N, Thomas L, Lackner T, et al. Factors associated with antiepileptic drug use among elderly nursing home residents. J Gerontol A Biol Sci Med Sci 2000;55:M384-92.

19. Aicardi J. Epilepsy in Children. $2^{\text {nd }}$ ed. New York: Raven Press; 1994. p. 39-42.

20. Salman MT, Akram MF, Rahaman S, Khan FA, Hassen MA, Kahan SW. Drug prescribing pattern in surgical wards of teaching hospital in Northern India. Indian J Pract Doct 2008;5:2.

21. Jimma University Specialized Hospital (JUSH), Jimma University. Available from: http://www.ju.edu.et/jimma-university-specialized-hospital-jush. [Last accessed on 2014 Apr 16].

22. Degu G, Tessema F. Biostatistics for health science students. Lecture Note Series. $1^{\text {st }}$ ed. Gondar University; 2005. p. 163-85.

23. Lim SH, Tan EK, Chen C. Pattern of anti-epileptic drug usage in a tertiary referral hospital in Singapore. Neurol J South East Asia 1997;2:77-85.

24. Arul Kumaran KS, Palanisamy S, Rajasekaran A. A study on drug use evaluation of anti-epileptics at a multispecialty tertiary care teaching hospital. Int J Pharm Tech Res 2009;1:1541-7.

25. Cleveland Clinic; Epilepsy Centre. Outcomes Report, 2011. Available from: http://www.my.clevelandclinic.org/neurological_institute/epilepsy/treatmentsservices/treatment-outcomes.aspx. [Last accessed on 2013 May 15]. 